\title{
If two are better than one, three are better than two
}

\author{
Chaim Locker, MD
}

\author{
From the Department of Cardiovascular Surgery, Mayo Clinic, Rochester, Minn \\ Disclosures: Author has nothing to disclose with regard to commercial support. \\ Received for publication Oct 6, 2017; accepted for publication Oct 7, 2017; available ahead of print Nov 7, 2017. \\ Address for reprints: Chaim Locker, MD, Department of Cardiovascular Surgery, Mayo Clinic, 200 First St SW, \\ Rochester, MN 55905 (E-mail: lekerlocker.chaim@mayo.edu). \\ J Thorac Cardiovasc Surg 2018;155:861-2 \\ $0022-5223 / \$ 36.00$ \\ Copyright (C) 2017 by The American Association for Thoracic Surgery \\ https://doi.org/10.1016/j.jtcvs.2017.10.009
}

In their article in this issue of the Journal, Luthra and colleagues ${ }^{1}$ report their results on an interesting controversial clinical question: "Does a third arterial conduit to the right coronary circulation improve survival?" Luthra and colleagues $^{1}$ performed a retrospective analysis of 598 patients who received 2 arterial grafts to the left anterior descending and circumflex coronary arteries, stratified by whether they received a saphenous vein graft (SVG); ( $\mathrm{n}=274)$ or a third arterial graft $(\mathrm{n}=324)$ to the right coronary artery (RCA). After conducting a detailed statistical analysis in matched patients ( $n=132$ pairs), they reasonably concluded that the addition of an arterial versus a venous graft to the RCA does not improve survival to the 7-year point. This finding is supported by several previous reports in the literature. ${ }^{2}$

Important points, however, need to be considered with regard to the study of Luthra and colleagues. ${ }^{1}$ First, mean follow-up was significantly different between the venous (85 months) and the arterial groups (51 months). This implies that the arterial technique was probably applied later. Furthermore, the survival curves were truncated at 84 months because of low numbers of patients at risk afterward. Numerous studies in literature report that the atherosclerotic obstructive process in SVGs will start to accelerate at around this time, and survival curves of SVGs will therefore exhibit a pronounced downward slope and separation from the multiarterial grafting curve at around 8 to 10 years. ${ }^{3}$ It may well take even longer to obtain a difference between 2 and 3 arterial grafts. Indeed, Luthra and colleagues ${ }^{1}$ acknowledge that there was an accelerated decline in survival in the SVG group after 84 months. We therefore can assume that with larger cohorts and longer follow-up, the superiority of 3 arterial grafts would become apparent. ${ }^{4}$

Second, there were 299 radial arteries and only 27 right internal thoracic arteries used overall in the arterial group. This difference might be too large to obtain a reliable statistical difference between right internal thoracic artery and radial artery grafts. It has been previously shown that no matter the coronary artery revascularized, the right internal thoracic artery has superior patency to both the radial artery and SVGs, as long as it is harvested in a skeletonized fashion and used appropriately.

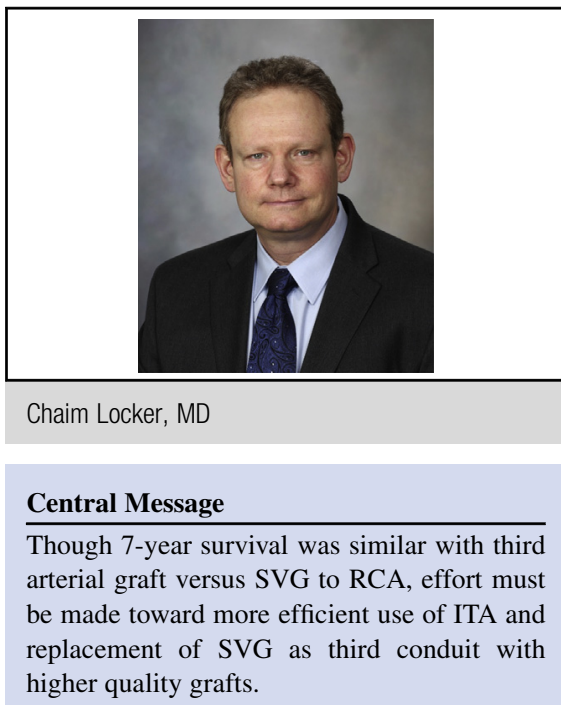

See Article page 855 .

Third, Luthra and colleagues ${ }^{1}$ have not provided a description of the surgical technique performed for RCA grafting. There may be major differences if arterial conduits are used as in situ or free grafts from the aorta versus free grafts in a composite $\mathrm{Y}$ anastomosis from left-sided grafts; if there are sequential grafts used to the circumflex and the RCA, if the internal thoracic arteries are harvested as pedicled or skeletonized, and if off-pump coronary artery bypass grafting technique is applied.

In a recent prospective, randomized clinical trial, Glineur and colleagues ${ }^{6}$ showed that the clinical benefit of the bilateral internal thoracic artery composite $\mathrm{Y}$ configuration seems independent of the quality of revascularization provided by the internal thoracic artery graft itself, but rather is related to the poor long-term outcome of the third complementary graft, more frequently needed with the in situ bilateral internal thoracic artery configuration. This implies that the quality of surgical revascularization could be optimized either by decreasing the number of coronary arteries that require a complementary third graft or by using as complementary third graft a conduit of superior quality. Composite bilateral internal thoracic artery grafting resulted in significant lower rates of major adverse cardiac and cerebrovascular events at 7 years than did conventional in situ bilateral internal thoracic artery grafting. ${ }^{6}$

If surgical revascularization aims to remain the superior treatment in coronary artery disease, efforts should be made toward a more efficient use of internal thoracic arteries, reduction of the need for a third complementary 
graft, and identification of the best alternative to SVG as the third graft material for complete revascularization of multivessel disease. ${ }^{7}$

\section{References}

1. Luthra S, Leiva-Juárez MM, Matuszewski M, Morgan IS, Billing JS. Does a third arterial conduit to the right coronary circulation improve survival? J Thorac Cardiovasc Surg. 2018;155:855-60.e2.

2. Di Mauro M, Contini M, Iacó AL, Bivona A, Gagliardi M, Varone E, et al. Bilateral internal thoracic artery on the left side: a propensity score-matched study of impact of the third conduit on the right side. J Thorac Cardiovasc Surg. 2009;137:869-74.

3. Locker C, Schaff HV, Dearani JA, Joyce LD, Park SJ, Burkhart HM, et al. Multiple arterial grafts improve late survival of patients undergoing coronary artery bypass graft surgery: analysis of 8622 patients with multivessel disease. Circulation. 2012;126:1023-30.

4. Gaudino M, Puskas JD, Di Franco A, Ohmes LB, Iannaccone M, Barbero U, et al. Three arterial grafts improve late survival: a meta-analysis of propensity-matched studies. Circulation. 2017;135:1036-44.

5. Locker $\mathrm{C}$. To skeletonize the internal thoracic artery or not to skeletonize? To be or not to be! J Thorac Cardiovasc Surg. 2018;155:229-31.

6. Glineur D, Boodhwani M, Hanet C, de Kerchove L, Navarra E, Astarci P, et al. Bilateral internal thoracic artery configuration for coronary artery bypass surgery. A prospective randomized trial. Circ Cardiovasc Interv. 2016;9: e003518.

7. Zhang M, Guddeti RR, Matsuzawa Y, Sara JD, Kwon TG, Liu Z, et al. Left internal mammary artery versus coronary stents: impact on downstream coronary stenoses and conduit patency. J Am Heart Assoc. 2016;5:e003568. 